\title{
A Porous Triphenylbenzene-Based Bicyclooxacalixarene Cage for Selective Adsorption of $\mathrm{CO}_{2} / \mathrm{N}_{2}$
}

\author{
Zhen Wang, ${ }^{\dagger} \dot{\dagger}$ Yi Luo, ${ }^{\dagger}, \dot{\dagger}$ Tian-Long Zhai, ${ }^{\ddagger}$ Hui Ma, ${ }^{\ddagger}$ Jing-Jing Chen, ${ }^{\star}$ Yuanjie Shu, ${ }^{\S}$ Chun Zhang, ${ }^{*}$
}

${ }^{*}$ College of Life Science and Technology, Huazhong University of Science and Technology, and National Engineering Research Center for Nanomedicine, Wuhan, 430o74, China.

$\S$ Xi’an Modern Chemistry Research Institute, Xi'an, 710065, China.

Supporting Information - Table of Contents

1. General information-------------------------------------------------------------------------S2

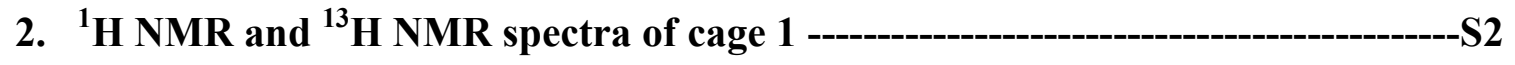

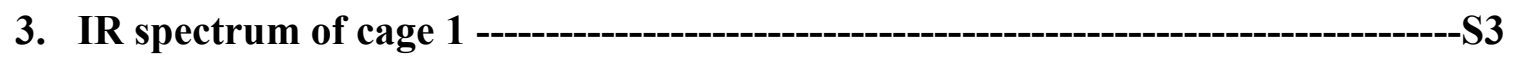

4. Crystal structure of cage 1 ----------------------------------------------------------------S4

5. PXRD plot of cage 1 ------------------------------------------------------------------------S6

6. Logarithmic plot of selectivity $\left(\mathrm{CO}_{2} / \mathrm{N}_{2}\right)$ versus $\mathrm{CO}_{2}$ uptakes of cage 1----------S7 


\section{General Information}

Materials obtained commercially were used without further purification. Melting points, taken on an electrothermal melting point apparatus, are uncorrected. ${ }^{1} \mathrm{H}$ NMR and ${ }^{13} \mathrm{C}$ NMR spectra were recorded on a DMX60o NMR. MALDI-TOF mass spectra were obtained on a BIFLEXIII mass spectrometer. The X-ray single crystal data were collected on Bruker Apex II CCD Area Detector. $\mathrm{CO}_{2}$ and $\mathrm{N}_{2}$ isotherms were measured at $273 \mathrm{~K}$ up to 1.13 bar using a Micromeritics ASAP 2020 volumetric adsorption analyzer with the degassing procedure.

Synthesis of cage 1. Under a dry argon atmosphere, a mixture of 1, 3, 5-tri(p-hydroxyphenyl) benzene 2 (100 mg, $0.28 \mathrm{mmol}$ ), 2, 6-dichloropyridine-3, 5-dicarbonitrile 3 (83 $\mathrm{mg}, 0.42 \mathrm{mmol}$ ), and anhydrous $\mathrm{Cs}_{2} \mathrm{CO}_{3}(182 \mathrm{mg}, 0.56 \mathrm{mmol})$ in anhydrous DMSO $(5 \mathrm{~mL})$ was stirred vigorously at room temperature for $4 \mathrm{~h}$ and then $40 \mathrm{~mL}$ water was added, the precipitate was collected and dried to give cage $\mathbf{1}(62 \mathrm{mg})$ as a white solid. Yield: 40.8\%. M. P. $>300^{\circ} \mathrm{C} .{ }^{1} \mathrm{H}$ NMR (60o MHz, DMSO- $\left.d_{6}\right): \delta 7.17(\mathrm{~d}, J=12.6 \mathrm{~Hz}, 12 \mathrm{H}), 7.68(\mathrm{~s}, 6 \mathrm{H})$, $7.78(\mathrm{~d}, J=13.2 \mathrm{~Hz}, 8 \mathrm{H}), 9.13(\mathrm{~s}, 3 \mathrm{H}) .{ }^{13} \mathrm{C}$ NMR (DMSO- $\left.d_{6} 15 \mathrm{O} \mathrm{MHz}\right): \delta$ 90.3, 114.3, 122.4, 123.5, 128.2, 138.0, 140.2, 151.4, 152.0, 165.1. IR (KBr): 2233, 1614, 1562, 1506, 1429, 1328, 1211, $1159 \mathrm{~cm}^{-1}$. MALDI-TOF-MS: m/z 1083 (M+). Anal. Calcd for $\mathrm{C}_{69} \mathrm{H}_{33} \mathrm{~N}_{9} \mathrm{O}_{6}: \mathrm{C}, 76.45 ; \mathrm{H}, 3.07$; N, 11.63. Found: C,76.73; $\mathrm{H}, 3.26 ; \mathrm{N}, 11.40$.

Crystallographic data for cage $1\left(\mathrm{C}_{69} \mathrm{H}_{33} \mathrm{~N}_{9} \mathrm{O}_{6}\right): M_{\mathrm{r}}=1084.04$, Monoclinic, Space group P $121 / \mathrm{n} 1$, a $=14.669(2), \mathrm{b}=32.397(5), \mathrm{c}=19.484(3) \AA, \alpha=90^{\circ}, \beta=111.648(3)^{\circ}, \gamma=90^{\circ}, V=8607(2) \AA^{3}, \mathrm{Z}=4, \rho_{\text {calcd. }}$ $=0.837 \mathrm{~g} / \mathrm{cm}^{3}, \mu=0.055 \mathrm{~mm}^{-1}$, reflections collected49581, data/restraints /parameters $15476 / 0 / 757$, GOF on $F^{2} 2.901$, final $\mathrm{R}_{1}=0.1434, \mathrm{wR} 2=0.4353, \mathrm{R}$ indices (all data): $\mathrm{R}_{1}=0.1547, \mathrm{wR} 2=0.4414$, largest diff. peak and hole: 0.452 and $-0.390 \mathrm{e} / \AA^{3}, \mathrm{CCDC}-1496231$. 


\section{2. ${ }^{1} \mathrm{H}$ NMR and ${ }^{13} \mathrm{C}$ NMR spectra of cage 1}
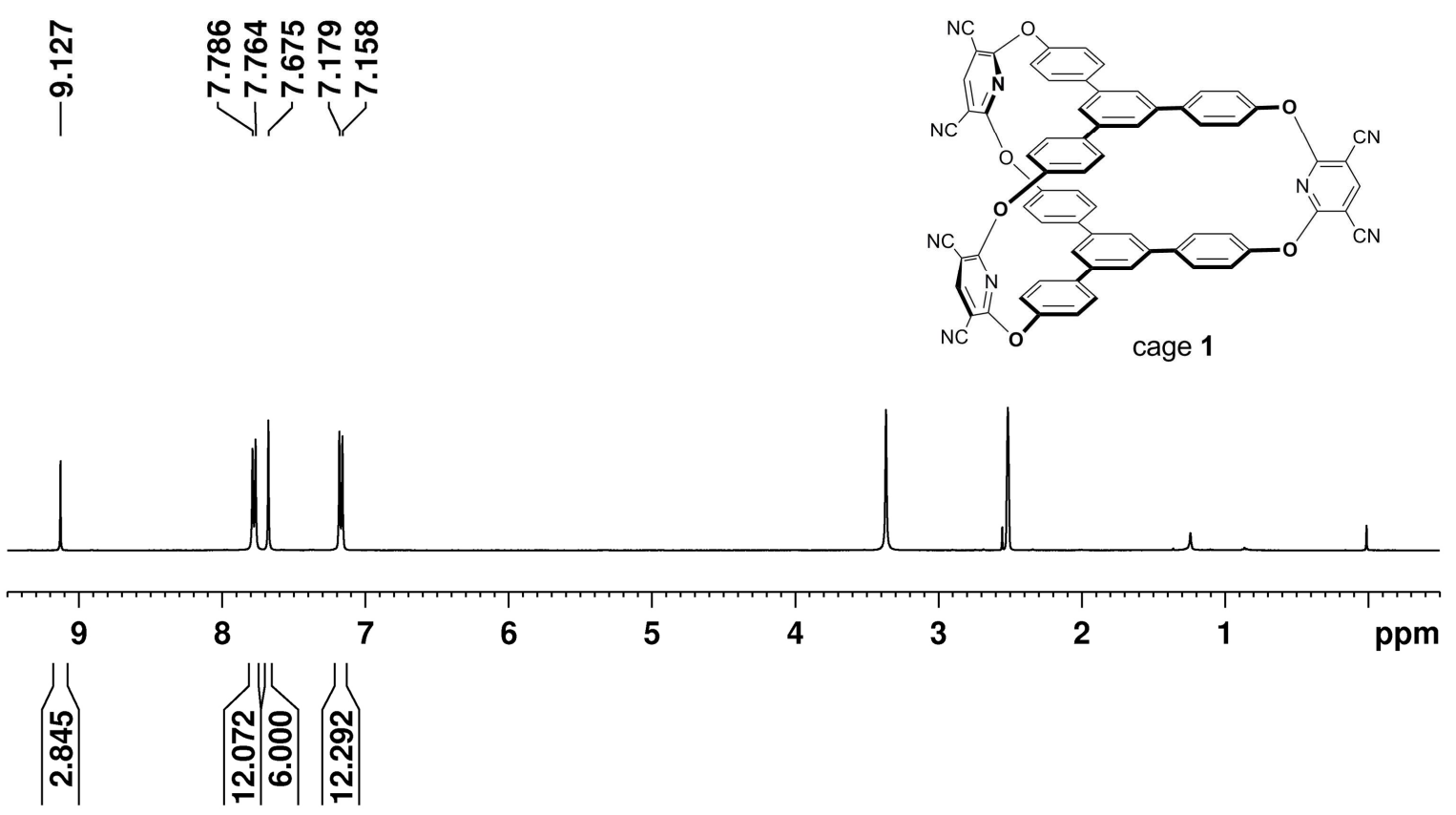

Figure $\boldsymbol{S} 1 .{ }^{1} \mathrm{H}$ NMR spectrum $\left(600 \mathrm{MHz}, \mathrm{DMSO}-d_{6}\right)$ of cage 1.

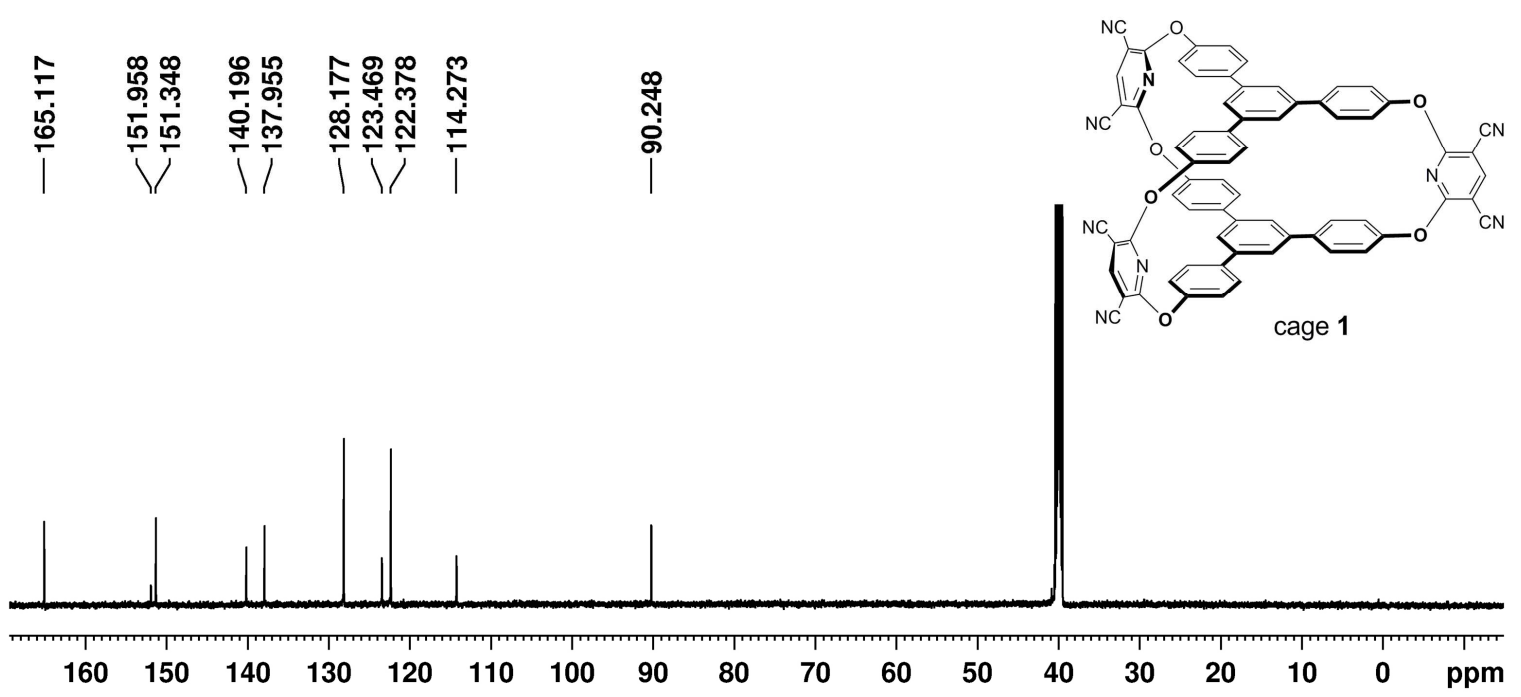

Figure S2. ${ }^{13} \mathrm{C}$ NMR spectrum $\left(150 \mathrm{MHz}, \mathrm{DMSO}-d_{6}\right)$ of cage 1. 


\section{IR spectrum of cage 1}

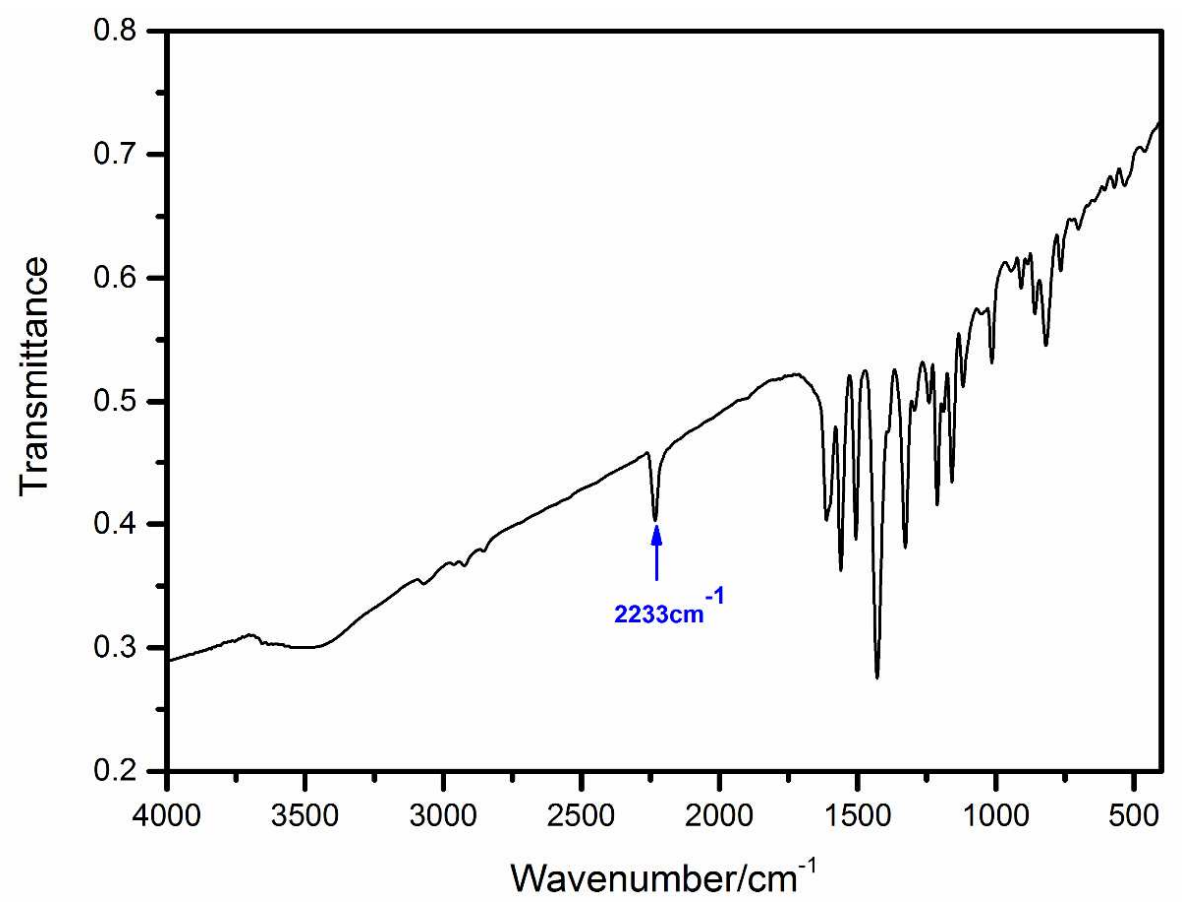

Figure S3. IR spectrum of cage 1.

\section{Crystal structure of cage 1}

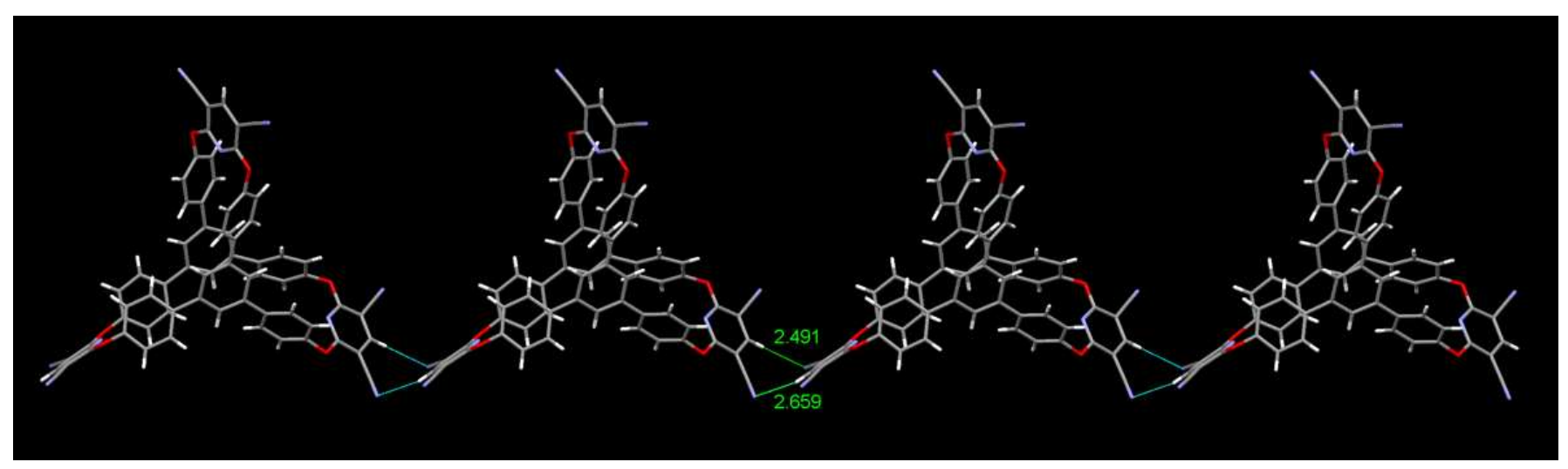

Figure S4. The infinite open chain structure of cage 1 by the virtue of a couple of $\mathrm{C}-\mathrm{H} \cdots \mathrm{N}$ interactions $\left(d_{\mathrm{H} \cdots \mathrm{N}}=2.66\right.$ and $\left.2.49 \AA\right)$. 


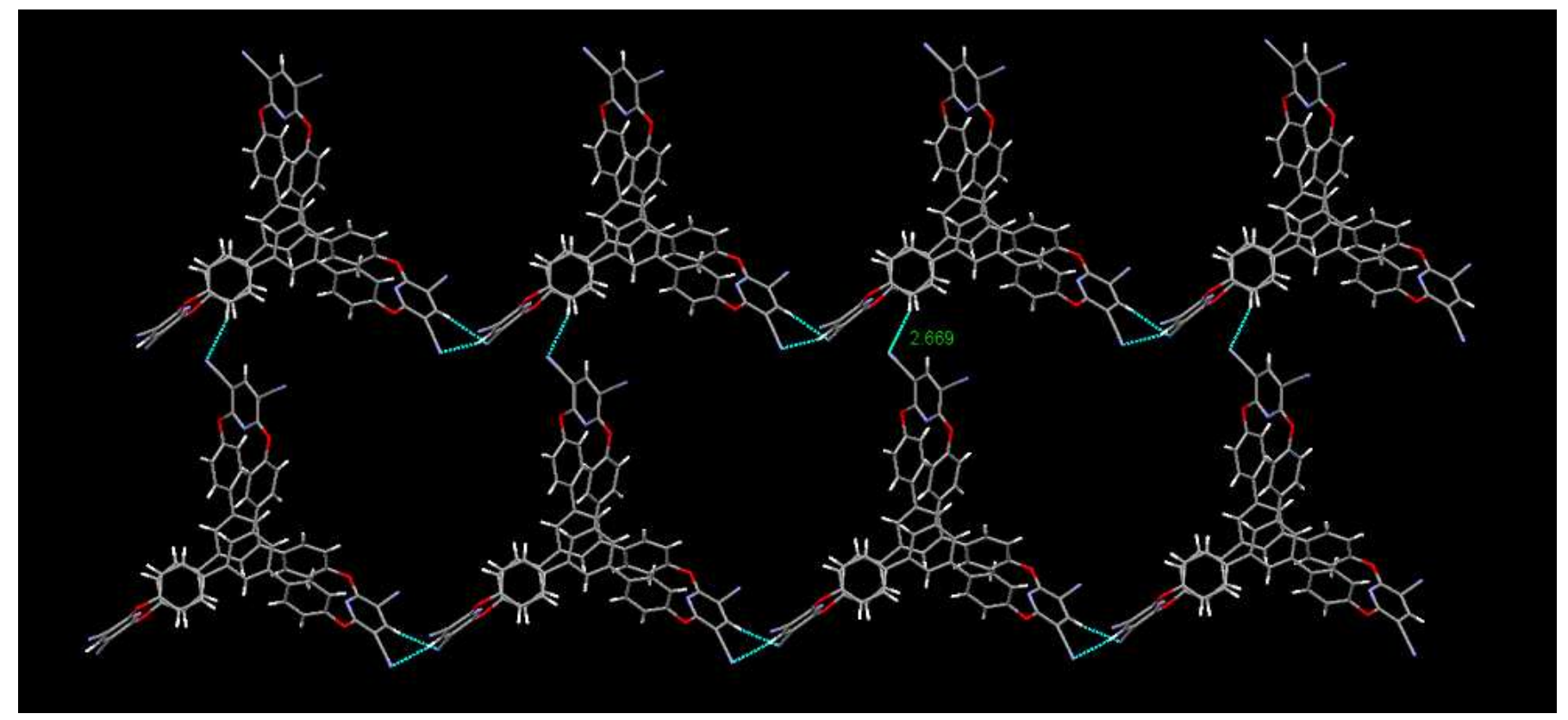

Figure S5. The a layered structure of cage 1by C-H $\cdots \mathrm{N}$ bonds $\left(d_{\mathrm{H} \cdots \mathrm{N}}=2.67 \AA\right)$.

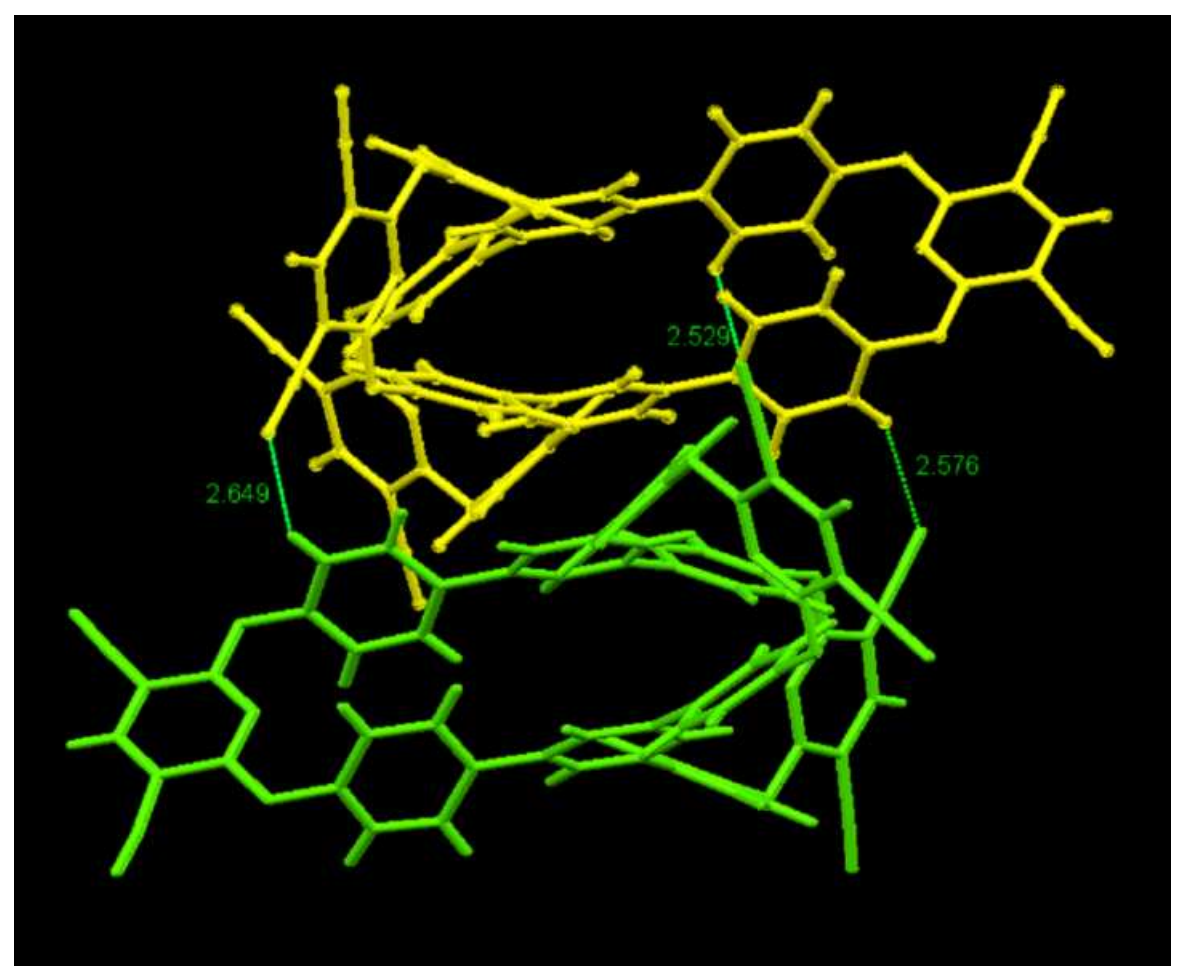

Figure S6. The porous three-dimensional AB layered structure of cage 1 by the interaction of C-H $\cdots \mathrm{N}$ bonds $\left(d_{\mathrm{H} \cdots \mathrm{N}}=2.53,2.58\right.$ and $\left.2.65 \AA\right)$. 


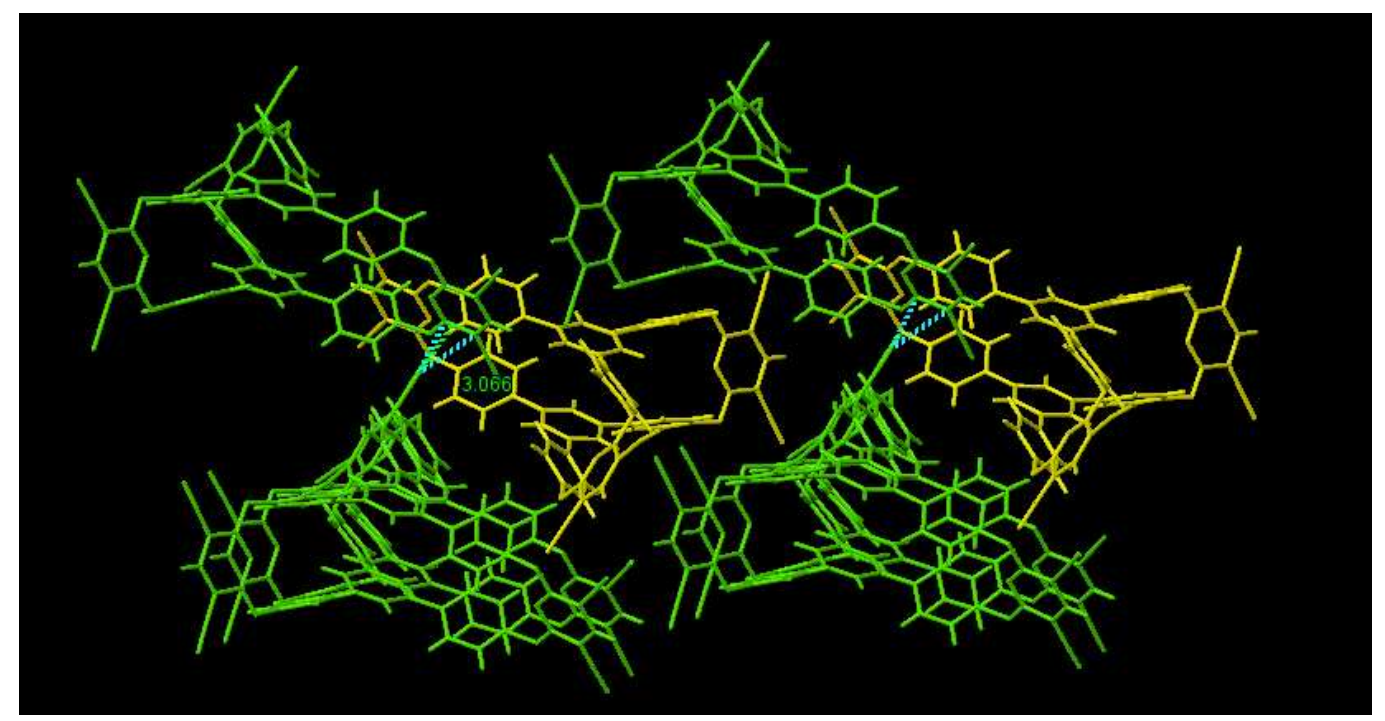

Figure S7. The interlaced network structure of cage 1 by the interactions of $\mathrm{C}-\mathrm{N} \cdots \pi$ interactions $\left(d_{\mathrm{N}} \cdots \pi\right.$ $=3.07 \AA$ ) between AA or BB layered structures.

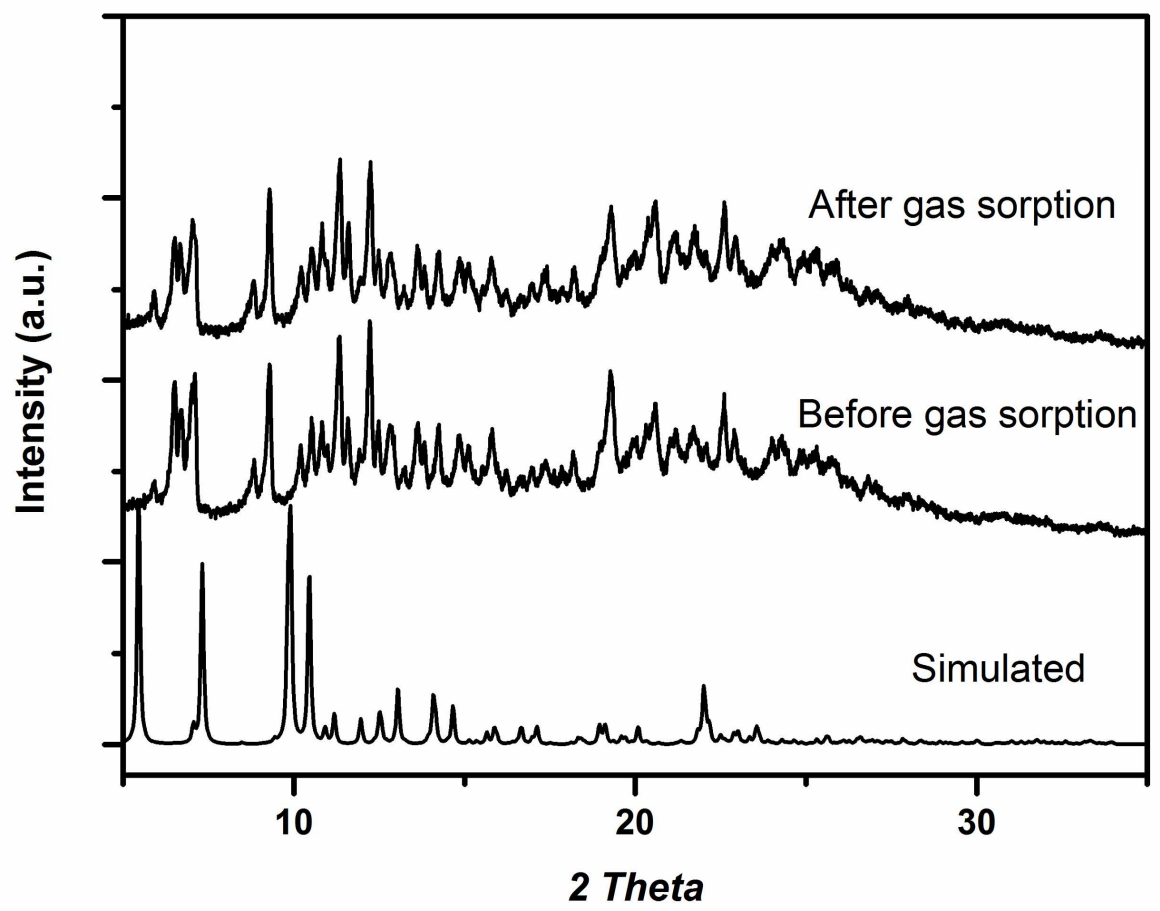

Figure S8. Powder X-ray diffraction patterns for cage 1 before (middle) and after (top) gas sorption. The simulated PXRD from the single crystal structure for cage $\mathbf{1}$ is shown as a comparison (bottom). 


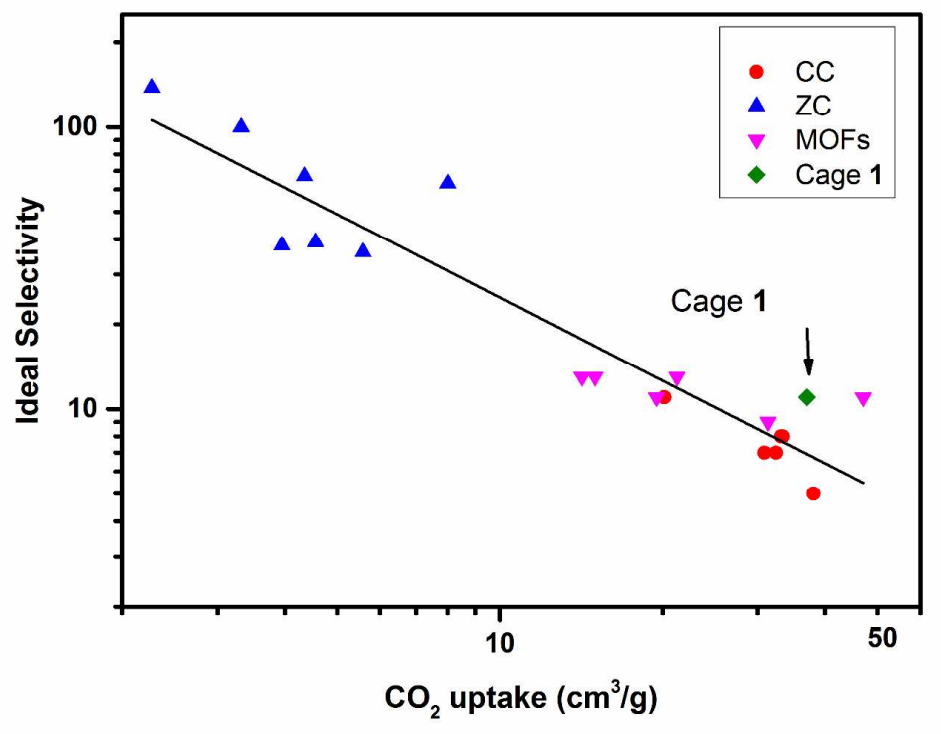

Figure S9. Logarithmic plot of ideal selectivity $\left(\mathrm{CO}_{2} / \mathrm{N}_{2}\right)$ versus $\mathrm{CO}_{2}$ uptakes with linear trend line showing cage compounds synthesized by Cooper group (red circles), cage compounds synthesized by Zhang group (blue triangles), and MOFs (pink triangles). 